\title{
Artroskopik tam kat rotator manşet tamiri ve klinik sonuçları
}

\section{Arthroscopic full thickness rotator cuff repair and the clinical results}

\author{
Selahattin Özyürek ${ }^{1}$, Kaya Turan², Haluk Çabuk² \\ ${ }^{1}$ Liv Hospital Ulus, Ortopedi ve Travmatoloji Kliniği, İstanbul \\ ${ }^{2}$ İstinye Üniversitesi, Liv Hospital Bahçeşehir, Ortopedi ve Travmatoloji Kliniği, İstanbul
}

\begin{abstract}
Rotator manşet yırtıkları ortopedi ve travmatoloji pratiğinde en sık karşılaşılan omuz problemidir. Akut travmatik yırtıklarda ve konservatif tedaviye yanıt alınamayan dejeneratif yırtıklarda cerrahi tedaviyle başarılı sonuçlar elde edilmektedir. Son 20 yıldır, artroskopik rotator manşet tamirleri, rotator manşet yırtıklarının cerrahi tedavisinde altın standart yöntem haline gelmiştir. Implant ve artroskopik görüntüleme teknolojisindeki gelişmelerle birlikte birçok farklı artroskopik teknik tam kat rotator kılıf tamirleri için tanımlanmıştır. En ideal tamir yöntemi hâlen tartışmalı bir konu olup yöntemlerin birbirlerine göre avantaj ve dezavantajları üzerine araştırmalar devam etmektedir. Bu yazımızda tam kat rotator manşet yırtıklarını tüm hatlarıyla ele alarak bu konudaki literatürün güncel bir derlemesini sunmayı amaçladık.
\end{abstract}

Anahtar sözcükler: omuz; manşet; rotator; tamir; artroskopik cerrahi
Rotator cuff tears are the most common shoulder problem in orthopedics and traumatology practice. Successful results are obtained with surgical treatment in acute traumatic tears and degenerative tears that do not respond to conservative treatment. For the last 20 years, arthroscopic rotator cuff repairs have become the gold standard method for the surgical treatment of rotator cuff tears. With advances in implant and arthroscopic imaging technology, many different arthroscopic techniques have been described for full-thickness rotator cuff repairs. The most ideal repair method is still a controversial issue, and research continues on the advantages and disadvantages of the methods compared to each other. In this article, we aimed to present an up-to-date review of the literature on this subject by dealing with full-thickness rotator cuff tears in all its lines.

Key words: shoulder; cuff; rotator; repair; arthroscopic surgery
$\mathrm{R}$ otator manşet yırtıkları en sık karşılaşılan omuz sorunudur. Dejeneratif veya travmatik zeminde oluşabilirler. Dejeneratif rotator manşet yırtıklarının yaşa bağlı olarak prevalansı \%15 ile \%51 arasında değişmektedir. ${ }^{[1]}$ Altmış beş yaş üstü bireylerde rotator manşet yırtıkları \%50 oranında bilateraldir. ${ }^{[2]}$ $\mathrm{Bu}$ lezyonların yalnızca üçte biri ağrıya neden olur. ${ }^{[3]}$ Tek taraflı omuz ağrısı olan 588 hasta üzerinde yapılan bir çalışmada, semptomatik yırtığı olan hastaların \%35,5'inin karşı omuzda da asemptomatik rotator manşet lezyonu olduğu gösterilmiştir. Semptomatik yırtıklar, asemptomatiklerden ortalama olarak \%30 daha büyük boyutta görülmektedir. ${ }^{[4]}$ Ağrının oluşması ve günlük aktivitelerde kısıtlılık lezyonun genişlemesiyle ilişkilidir. Bu durum yalnızca tam kat bir lezyonun boyutunun artması değil, aynı zamanda kısmi bir lezyonun tam kata ilerlemesi anlamına gelmektedir.
[5] Yaş, dominant taraf, rotator manşet kaslarındaki yağlı dejenerasyon ve glenohumeral kinematikteki değişiklikler gibi faktörler de ağrı oluşmasına neden olabilmektedir. ${ }^{[6]}$ Asemptomatik yırtıkların yarısından fazlasının yaklaşık üç yıl içinde semptomatik hâle geldiği öngörülmektedir. ${ }^{[7]}$ Geçmişte, bazı yazarlar rotator manşetin dejeneratif lezyonlarının primer olarak supraspinatus tendonunu ilgilendirdiğini ve tipik olarak humeral yapışma yerinin ön kısmında biseps uzun başı yakınından başlayıp, posteriora doğru ilerlediğini göstermişlerdir. ${ }^{[8]}$ Daha yakın tarihli çalışmalar ise bundan farklı olarak rotator manşet yırtıklarının infraspinatus tendonundan başladığını göstermiştir. ${ }^{[9]}$ Kim ve ark. kısmi veya tam kalınlıkta rotator manşet yırtığı olan 360 omuz üzerinde yaptıkları bir ultrason çalışmasında, lezyonların, biseps tendonu uzun başının 13-17 $\mathrm{mm}$ arkasında, supraspinatus ve infraspinatus ten-

İletişim / Contact: Doç. Dr. Selahattin Özyürek•E-posta / E-mail: fsozyurek@yahoo.com

ORCID iD: Selahattin Özyürek, 0000-0002-7686-728X • Kaya Turan, 0000-0002-0547-995X • Haluk Çabuk, 0000-0002-1413-2149

Geliş / Received: 29 Ocak 2022 • Kabul / Accepted: 16 Şubat 2022 
donlarının birleşimindeki bir bölgede başladığını ortaya koymuşlardır. ${ }^{[10]}$ Bu sonuçlar, Burkhart ve ark. tarafından geliştirilen rotator kablo-kresent teorisiyle de doğrulanmaktadır. ${ }^{[11]}$

Travmatik rotator manşet yırtıkları, omuz abduksiyon ve dış rotasyondayken oluşan travmalar sonrası meydana gelir ve genellikle görülme yaş ortalaması 55 civarındadır. Travmatik yırtıklar dejeneratif yırtıklardan ortalama 10 yaş daha genç olan bireylerde görülür. Travmatik yırtıkların boyutu dejeneratiflerden daha büyüktür ve sıklıkla subskapularis tendonunu da içerir. Olguların \%50'si büyük veya masif yırtıklardır. Erken dönemde cerrahi tamir, travmatik yırtıklarda çok iyi bir sonuç sağlamaktadır çünkü hastalar daha gençtir, daha az retraksiyon ve yağlı dejenerasyon eşlik etmektedir. Travmatik yaralanmaların tamiri sonrası başarılı sonuç oranları \%65 ile \%69 arasında değişmektedir. ${ }^{[12]}$

\section{PATOFIZYOLOJi}

Rotator manşet, skapulanın arka yüzünden başlayıp büyük tüberküle yapışan supraspinatus, infraspinatus, teres minör tendonlarından ve skapulanun ön yüzünden başlayıp küçük tüberküle yapışan subskapularis tendonundan oluşan muskulotendinöz bir yapıdır.

Rotator kılıf hastalıkları, intrinsik, ekstrensek ve sekonder nedenlerle meydana gelmektedir. Rotator kılıf, omuz eklemi hareketlerinin tüm fazlarında humerus başını glenoid üzerinde santralize eden, dinamik bir stabilizatördür. Biyomekanik açıdan, temel fonksiyonu koronal (superior-inferior) ve transvers (anterior-posterior) planlarda dengeleyici kuvvetler oluşturarak, glenohumeral eklem kinetiğine katkı sağlamaktır. Bu kuvvetler, koronal planda deltoid ile rotator kılıfın üst kısım kaslarını, transvers planda ise subskapularis (önde) ile arka taraf rotator kılıf kaslarını (infraspinatus ve teres minör) dengelemektedir.

Burkhart ve ark., 1993'te rotator kablo ve kresent kompleksi teorisini tanımlamışlardır. ${ }^{[11]}$ Sağlam rotator manşet, avasküler bölge sınırında korakohumeral ligamanın kavisli bir kablo şeklinde kalınlaşmasıyla karakterizedir. Önde, büyük tüberküle (biseps uzun başının hemen arkasında) ve arkada infraspinatus tendonunun alt sınırına yakın yapışır. Bu yapı bir suspansiyon köprüsü görevi yapar. Rotator manşet kaslarının aktive olmasıyla oluşan tendinöz bölgedeki stres rotator kabloya transfer olur, böylece zayıf ve ince olan avasküler bölgeye ulaşan stres azaltılır. Suspansiyon köprü ve rotator kablo teorisi aynı zamanda, küçük ve orta boyuttaki rotator kılıf yırtıklarında ve fonksiyonel tamir uygulanan masif yırtıklarda aktif hareketlerin neden kısıtlanmadığını da açıklamaktadır. ${ }^{[13]}$
Patolojik açıdan, rotator manşet yırtıklarının genişliği ve derinliği farklılık göstermektedir. Kısmi yırtıkları eklem ya da bursal yüzde veya intratendinöz olabilmekteyken, tam kat yırtıklar tendonun tümünü ilgilendirmektedir. Cerrahi tekniklerin gelişimiyle anatomik yapılarla ilgili daha detaylı bilgilere sahip olunması, yırtıkların daha detaylı bir şekilde sınıflandırılmasını ve özellikle lezyonların tamir edilebilme olasılıklarını belirlemeyi sağlamıştır. Günümüzde tam kat yırtıklar bölgesine, şekline, alanına, retraksiyon miktarına ve redükte edilebilirliğine göre tanımlanmaktadır.

Matsen ve ark.'nın yırtığın genişliğine göre ve etkilenen yapılara göre yaptıkları sınıflandırmada; $;^{[8]}$

- $\quad$ Evre 1: Tam kat supraspinatus yırtığı $(<2 \mathrm{~cm})$

- Evre 2: Tam kat suprapinatus + kısmi infraspinatus yırtığı $(2-4 \mathrm{~cm})$

- $\quad$ Evre 3: Tam kat supraspinatus + infraspinatus + subskapularis yırtığı $(>4 \mathrm{~cm})$

- Evre 4: Rotator manşet yırtık artropatisi

Snyder, yırtık lokalizasyonuna ve şiddetine göre kısmi artiküler (A), kısmi bursal taraf (B) ve tam kat (C) olacak şekilde bir sınıflandırma tanımladılar. Tam kat yırtıkları da kendi arasında alt gruplara ayırmıştır: ${ }^{[14]}$

- C/0: Kısmi artiküler ve bursal yüz

- $\mathrm{C} / 1:<1 \mathrm{~cm}$ tam kat yırtık

- $\quad C / 2$ : Minimal retraksiyon gösteren ve genellikle sadece supraspinatusu ilgilendiren $2-3 \mathrm{~cm}$ tam kat yırtık,

- $\quad \mathrm{C} / 3$ : Supraspinatusun ve infraspinatusun bir kısmını ilgilendiren yırtıklar

- C/4: En az iki tendonu ilgilendiren masif yırtık

Davidson ve Burkhart, artroskopi sırasında yırtığın şeklinin geometrisine göre bir sınıflandırma geliştirmiştir. ${ }^{[15]}$ Her bir lezyon için belirli bir tamir türü önererek uygun gerginlikte tamir ve kuvvetlerin dengelenmesini amaçlamışlardır. Sınıflamada;

- Tip 1, kresentik: Boyutundan bağımsız olarak mediolateral mobilitesi iyi olan ve minimal gerginlikte tamir edilebilir lezyonlar

- Tip 2, U, L ve ters L: U şekilli yırtıkların kresentik yırtıklardan daha fazla medial uzanımı vardır; apeksi glenoid rimine yakındır. $L$ ya da ters $L$ yırtıklar mobil yaprak ile karakterizedir. $L$ şekillilerde ön yaprak daha mobil iken, ters L'de ise arka yaprak daha mobildir. Yırtığın şeklini ve apeksini belirlemek, direkt tendon kemik onarımı ya da gerilimi azaltmak yırtığın serbest kenarını foot- 
printe doğru yaklaştırmak için kullanılan kenar yaklaştırma tekniği uygulaması kararını vermek için önemlidir.

- Tip 3, masif, retrakte ve immobil: Bu yırtıklar mediolateral ya da ön arka immobilizasyon ile karakterizedir.

- Tip 4, rotator manşet yırtık artropatisi

\section{KLINIK MUAYENE}

Klinik muayene her zaman, aktif ve pasif eklem hareket açıklığı değerlendirmesi, subakromial krepitasyon varlığının belirlenmesi ve olası bir kas atrofisi ya da deformitesi açısından her iki omzun birlikte inspeksiyonu ile başlar. Ayrıca şüphelenilen lezyona yönelik spesifik testlerin de yapılması gereklidir. Kas gücünün belirlenmesi de tanıya giden yolda oldukça kritiktir. Aşağıda sık kullanılan klinik testler listelenmiştir:

- Yocum testi: Supraspinatus hassasiyeti ve kuvvetini değerlendirir.

- Jobe testi: Bu test hastaya skapular planda kolunu dirence karşı abduksiyona zorlaması istenerek uygulanır. Kol iç rotasyonda (başparmak aşağıyı gösterecek şekilde) olmalıdır. Ağrının ortaya çıkması veya gücünde azalma olması supraspinatus tendinopatisini ya da yırtığını gösterir.

- Infraspinatus testi: Hastadan dirseği adduksiyondayken dirence karşı omzunu dış rotasyona zorlaması istenerek uygulanır. Ağrı olması veya güç kaybı infraspinatus lezyonunu gösterir.

- Patte testi: Hastadan omzu abduksiyonda ve dirseği $90^{\circ}$ fleksiyondayken dirence karşı dış rotasyon uygulaması istenerek uygulanır. Yine ağrı veya güç kaybı olması infraspinatus lezyonunu gösterir.

- Drop-arm testi: Muayeneyi yapan, hastanın yanında durur; hastanın kolu dirsek $90^{\circ}$ fleksiyondayken, skapular planda omuz $90^{\circ}$ öne elevasyonda ve tam dış rotasyondayken hastadan dış rotasyonu devam ettirmesi istenir. Sonra dirsek desteklenirken el bileği desteği bırakılır. Eğer ön kol düşerse test pozitiftir ve infraspinatus yırtığını gösterir.

- Diş rotasyon gecikme testi: Muayeneyi yapan hastanın arkasında durur. Hastanın kolu, dirsek $90^{\circ}$ fleksiyonda, skapular planda $20^{\circ}$ öne elevasyonda ve tamamen dış rotasyona alınır. Hastadan dış rotasyonu ve öne elevasyonu devam ettirmesi istenerek el bileğindeki destek bırakılır. Eğer ön kol düşerse test pozitiftir ve supraspinatusla birlikte infraspinatus yırtığını gösterir.
Subskapularis tendonu lift-off, Napoleon ve bearhug testleri ile, biseps uzun başı patolojileri ise avuç içi-yukarı, Yergason, aktif-pasif ve Ludington testleri ile değerlendirilir.

Tam kat rotator manşet yırtığı olan hastalarda oluşan fonksiyonel kısıtlılıkların sadece muskulotendinöz bileşkeden kaynaklı ağrı veya güç kaybından değil, aynı zamanda eklem kinematiğinde etkili dengeleyici güçlerde oluşan uyumsuzluktan da kaynaklanabileceği mutlaka akılda tutulmalıdır. ${ }^{[13]}$

\section{GÖRÜNTÜLEME}

\section{Konvansiyonel Radyoloji}

Standart omuz serileri akromiohumeral mesafeyi ve akromion morfolojisini değerlendirmede, osteoartrit, os akromiale veya kalsifik tendinit gibi eşlik eden diğer patolojik durumları saptamada yararlıdır.

\section{Ultrasonografi}

Non-invaziv ve düşük maliyetli olmasından dolayı sıkça tercih edilmektedir. Tam kat yırtıklarda yüksek duyarlılık ve özgüllük bildiren çalışmalar mevcuttur. Manyetik rezonans (MR) ve MR artrografi ile karşılaştırma yapılan çalışmalarda duyarlılık ve özgüllük tam kat yırtıklarda MR'ye oldukça yakın seviyede bulunmuştur. Ok ve ark. lezyonun boyutunu belirlemede MR'nin daha üstün olduğunu ortaya koymuşlardır. ${ }^{[16]}$ Yağlı dejenerasyon belirlemede ise MR ile aynı duyarlılık ve özgüllüğe sahiptir. ${ }^{[17]}$ Ancak akıldan çıkarılmaması gereken, ultrason etkinliğinin uygulayıcıya da bağlı olduğudur.

\section{Manyetik Rezonans}

Rotator manşet yırtıklarını tespit etmede çok hassas olmasına rağmen oldukça pahalı bir yöntemdir. Son çalışmalarda 3.0 Tesla yüksek çözünürlükte MR çekilmesi önerilmektedir. Koronal oblik, sagital ve aksiyal seriler ile subakromial bursa, tendonların kalınlıkları değerlendirilebilmekte ve tendon yırtıkları tespit edilebilmektedir.

Yırtığın hangi tendonları ilgilendirdiği ve retraksiyon miktarına göre yapılan Patte sınıflaması en sık kullanılan sınıflama yöntemidir. ${ }^{[18]}$ Sagital plandaki etkilenen tendon sayısına göre lezyonlar gruplandırılır:

- Segment 1: Subskapularis

- Segment 2: Rotator interval

- Segment 3: Supraspinatus

- Segment 4: Supraspinatus ve infraspinatusun ön kısmı

- Segment 5: Supraspinatus ve infraspinatus 
- $\quad$ Segment 6: Masif yırtık

Tendon retraksiyonu koronal plandan değerlendirilerek gruplandırılır:

- $\quad$ 1. Derece: Retraksiyon yok

- 2. Derece: Humerus başına retrakte

- 3. Derece: Glenoide retrakte

Son dönemde, Davidson ve Burkhart ${ }^{[15]}$, ameliyat öncesinde MR'de lezyonları geometrisine göre, koronal T2 kesitlerdeki maksimum yırtık uzunluğu (U) ve aksiyel T2 kesitlerdeki maksimum yırtık genişliklerini (G) ölçerek sınıflandırdılar.

- $\quad$ Tip 1: $U \leq G$ ve $U<2 \mathrm{~cm}$

- $\quad$ Tip 2: $U>G$ ve $G<2 \mathrm{~cm}$

- Tip 3: $U \geq 2 \mathrm{~cm}$ ve $\mathrm{G} \geq 2 \mathrm{~cm}$ (Bu grupta interval kaydırma ya da parsiyel tamir gibi ek girişimler olguların \%75'inde gerekmektedir.)

- $\quad \mathrm{U} \geq 3 \mathrm{~cm}$ ve $\mathrm{G} \geq 3 \mathrm{~cm}$ ise ek girişimler $\% 100$ gerekli olmaktadır.

- $\quad$ Tip 4: Glenohumeral artrit ve subakromial aralığın kapanması

MR ayrıca yağlı dejenerasyon ve kas atrofisini de sagital plan görüntülerinde değerlendirilmesini sağlamaktadır. Goutallier, ilk olarak yağlı dejenerasyon sınıflandırmasını bilgisayarlı tomografi (BT) artrografide tanımlamıştır. ${ }^{[19]}$ Ardından Fuchs MR ile daha iyi gözlemciler arası uyumun sağlandığını göstermiştir. ${ }^{[20]}$ Goutallier yağlı dejenerasyonu beş evrede tanımlamıştır:

- $\quad$ Evre 0: Normal kas (kas içerisinde yağ yok)

- $\quad$ Evre 1: Yer yer yağlı çizgilenmeler

- $\quad$ Evre 2: <\%50 yağlı infiltrasyon (yağ<kas)

- $\quad$ Evre 3: \%50 yağlı infiltrasyon (yağ=kas)

- $\quad$ Evre 4: >\% 50 yağlı infiltrasyon (yağ>kas)

Sonraki dönemde yapılan bazı çalışmalarda, bu sınıflamanın güvenilirliğinin zayıf olduğu raporlanmış ve sınıflama basitleştirilerek üç evre tanımlanmıştır: ${ }^{[21]}$

- Yağlı infiltrasyon yok ya da çok az

- Orta seviyede yağlı infiltrasyon

- Kastan daha fazla yağ

\section{Bilgisayarlı Tomografi}

Tam kat yırtıkların tanısında oldukça yararlıdır. Eklem içi kontrast madde uygulamasıyla (BT-Artrografi) duyarlılık ve özgüllük artmaktadır. Buna rağmen MR ile kıyaslan- dığında, tanı doğruluk oranı daha azdır ve MR çekilemeyen hastalarda tercih edilmesi önerilmektedir. ${ }^{[22]}$

\section{MR Artrografi}

En yüksek duyarlılık ve özgüllüğe sahip olmasına rağmen invaziv ve pahalı bir tanı aracıdır. Rotator manşet yırtıkları tanısındaki rolü kısıtlı da olsa, glenoid labrum patolojilerinin değerlendirilmesinde altın standarttır. ${ }^{[22]}$ Bazı çalışmalar ise tamir edilmiş yırtıkların iyileşme durumunun değerlendirilmesinde önemli bir rolü olduğunu bildirmektedir. ${ }^{[23]}$

\section{TEDAVI PLANLAMA}

\section{Endikasyon ve Kontrendikasyonlar}

Rotator manşet yırtıklarıyla günlük klinik pratikte sıkça karşılaşılmasına rağmen tedaviyle ilgili henüz bir ortak görüş mevcut değildir. Son dönemdeki bazı derleme çalışmaları küçük veya asemptomatik yırtıklarda fizik tedavi, steroid olmayan anti-enflamatuvar ilaç tedavisi, subakromial kortikosteroid, hyaluronik asit enjeksiyonları gibi cerrahi dışı tedavilere dikkat çekse de orta ve uzun dönem takiplerde cerrahi tedavi daha iyi sonuçlar sağlamaktadır. ${ }^{[24]}$ Buna göre cerrahi endikasyonlar şu şekilde sıralanabilir:

- Konservatif yöntemlere yanıt vermeyen küçük yırtıklar

- Semptomatik hale gelen asemptomatik yırtıklar

- Orta ya da geniş boyuttaki semptomatik veya asemptomatik yırtıklar

- Akut travmatik yırtıklar (<4 ay)

- Masif yırtıklar

- Goutallier sınıflamasına göre Evre 2'den fazla yağlı dejenerasyon

- Kronik travmatik yırtıklar

Kontrendikasyonlar ise:

- Eklem sertliği (pasif eklem hareket açıklığının kaybı)

- $\quad$ ileri derecede osteoartrit

- Glenoide kadar tendon retraksiyonu

- Ileri derecede yağlı dejenerasyon

- Illeri derecede kas atrofisi

- Devam eden sistemik ya da lokal enfeksiyonlar

- Eşlik eden nörolojik hastalık

şeklinde sıralanabilir. ${ }^{[24]}$ 


\section{KARAR VERME ALGORITMASI}

Uygun tedavi algoritmasını oluşturabilmek için öncelikle hastanın hassas bir şekilde anamnezini almak ve detaylı klinik muayenesini yapmak gerekir. Klinik şüphe duyulan lezyonlara yönelik yapılan görüntüleme yöntemleriyle tanı doğrulanır. Spesifik radyografiler ve MR eğer rotator manşet hastalığından şüpheleniliyorsa istenmelidir. Bazı nadir durumlarda, kas atrofisi ve/veya nörolojik semptomlar varsa elektromiyografi altta yatan nöromuskuler bir hastalığı ekarte edebilir.

Ağrının azaltılması ve fonksiyonel iyileşme rotator manşet tamirinin ana hedefidir. Cerrahi tedavi sonucu birtakım faktörlerden etkilenebilmektedir, bunlar uygun tedavi planlaması için önceden değerlendirilmelidir. Bu faktörler; hastanın yaşı, fonksiyonel seviyesi, semptomların süresi, tendon retraksiyonu, yağlı infiltrasyon ve kas atrofisidir.

Son dönemde 389 atravmatik semptomatik rotator manşet yırtığı olan hasta üzerinde yapılan bir çalışmada, ağı ve fonksiyonel kısıtlılık açısından modifiye edilebilir bazı faktörler ortaya konulmuştur. Bunlar skapulotorasik diskinezi, öne elevasyon ve aktif abduksiyon kısıtıığı veya güç kaybıdır. Yaş, semptomların süresi, yırtık boyutu, subakromial aralığın daralması ve sigara alışkanlığı gibi faktörlerin kötü sonuçlar ile doğrudan bir ilişkisi ortaya konamamıştır. ${ }^{[6]}$ Ayrıca bu çalışma, 60 yaş üzerinde veya daha genç ancak fonksiyonel seviyesi düşük hastalardaki küçük asemptomatik yırtıklarda başlangıçta cerrahi dışı yöntemlerin uygulanmasının uygun olabileceğini öne sürmektedir. Bu tür vakalarda, skapulotorasik kinematikteki sorunlar düzeltilerek, ağrı azaltılabilir ve fonksiyonel iyileşme sağlanabilir. Ĕger konservatif tedavi başarısız olursa cerrahi tedavi seçeneği düşünülmelidir. Tam tersi olarak, yüksek beklentili ve fonksiyonel seviyedeki hastalarda cerrahi tedavi ilk seçenektir. Orta ya da geniş boyutlu, semptomatik rotator manşet yırtığı, kontrendikasyon yoksa mutlaka cerrahi tamir gereklidir. ${ }^{[25]}$

\section{ARTROSKOPIK TAMIR}

\section{Hasta Pozisyonlama}

Cerrahi genel anestezi veya interskalen blok gibi rejyonel anestezi altında uygulanabilir. İnterskalen blok hastanın pozisyonlamaya yardımcı olması ve daha uzun süre etkili ameliyat sonrası ağı kontrolü sağlaması açısından tercih edilebilir. Hasta şezlong pozisyonu (Şekil 1) ya da lateral dekubit pozisyonda cerrahın tercihi doğrultusunda hazırlanabilir. Anestezi altında eklem hareket açıklığı muayenesi tekrarlanarak eklem sertliği ekarte edilir.

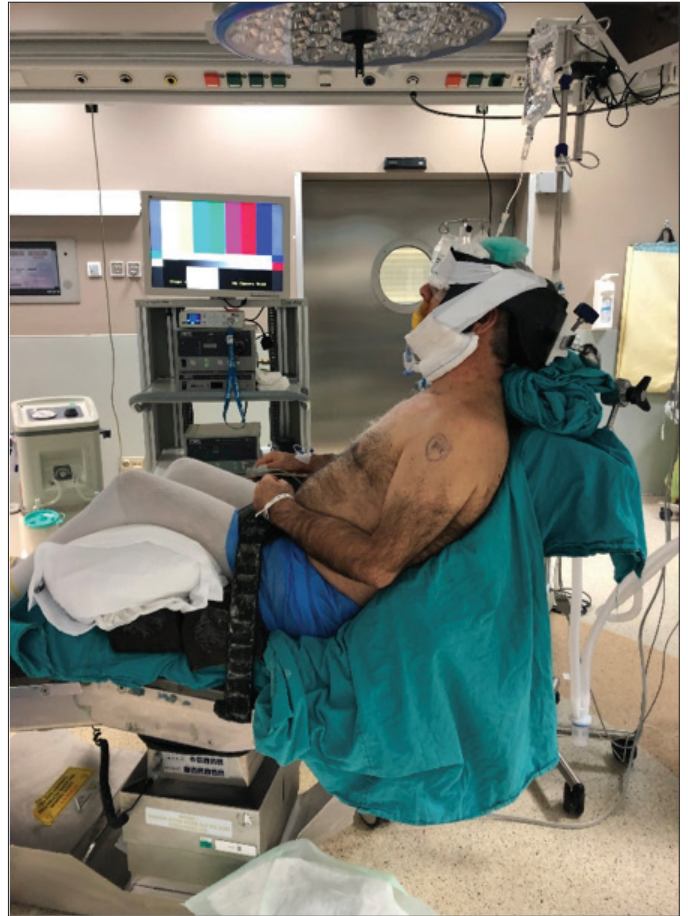

Şekil 1. Şezlong pozisyonu.

\section{Portal Yerleşimi}

Kemik yapıdaki mihenk noktalarını (spina skapula, akromion, klavikula, korakoid çıkıntı vb.) cilt kalemiyle işaretlemek uygun portal yerleşimi açısından faydalıdır. Standart olarak artroskopik tamirde genellikle kullanılan dört portal vardır (Şekil 2). Geniş ya da masif yırtıklar uygun ankor yerleşimi ve sütür taşımak için ek portaller gerekebilir.

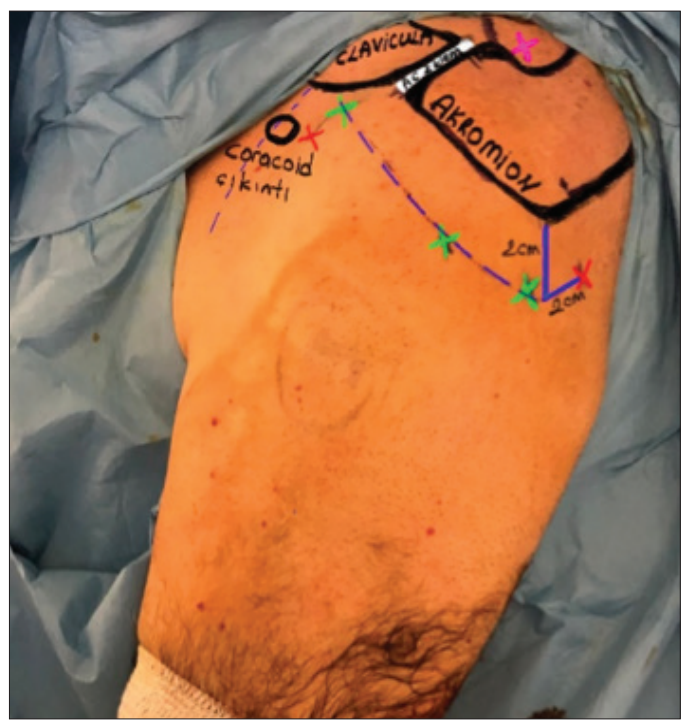

Şekil 2. Artroskopi portalleri. 
Posterior portal: Bu portalle eklem içi tanısal artroskopi yapılır. Bazen sütür geçirmek ya da taşımak için de kullanılabilir.

Anterior-superior portal: Dıştan-içe tekniğiyle rotator intervalden eklem içine doğru açılır. Bu portal üzerinden biseps uzun başı ve subskapularis lezyonlarına müdahale edilmekte, aynı zamanda sütür taşımak ve düğümlemek için kullanılmaktadır.

Standart lateral portal: Yırtı̆̆ın yerini, şeklini ve mobilitesini görüntülemek için kullanılır. Sütür yerleştirmek, radyofrekans ya da shaver cihazlarını yönetmek için kullanılan temel müdahale portalidir.

Superior-lateral portal: Doğru sütür ankor yerleşimi için kullanılır. 18 gauge (g) iğne ile akromiyon lateral kenarının orta $1 / 3$ 'lük bölgesinden, yırtığın ortasına gelecek şekilde açılır.

\section{Tanısal Artroskopi ve Patolojiyi Tanımlama}

Tüm artroskopik işlemler öncelikle tanısal değerlendirmeyle başlar. Posterior portal açıldıktan sonra, skop ekleme yerleştirilerek eklem sıvı ile şişirilir. Eklem içi yapıların değerlendirilmesi şu sırayla yapılır; subskapularis tendonu, bisepsin uzun başı ve pulleyi, rotator manşetin eklem yüzü, humeral ve glenoid kıkırdak yüzeyleri ve glenoid labrum. İnstabilite hikâyesi ya da klinik bulguları olmayan yaşlı hastalarda, glenohumeral ligamanların detaylı değerlendirilmesi gerekli değildir. Subakromial alana geçmeden önce subskapularis ve/veya biseps uzun başındaki kombine lezyonların ya da eklem tarafındaki kısmi yırtıkların işaretlenmesinde fayda vardır. Eklem içi değerlendirme tamamlandıktan sonra yine posterior portalden subakromial alana geçiş yapılır. Alternatif olarak yeni bir postero-lateral portal açılarak cerrahi alana daha iyi hâkim olunabilir. İçeriye basınçlı sıvı akışı subakromial alanı genişletir. Lateral portal üzerinden tendon uçları, footprint ve büyük tüberkül iyi görülebilecek kadar yeterli subakromial bursektomi bir shaver ya da radyofrekans cihazıyla yapılır. Skop lateral portale alınarak subakromial bursanın posteriorda görüşü engelleyen perdesi daha kolay temizlenebilir. Bazı cerrahlar, tendon iyileşmesine katkı sağladığı için subakromial bursanın mümkün olduğunca korunmasını önerse de, uygun bir tamir yapabilmek için arka taraf rotator manşetin iyi görülmesi önemlidir.

\section{Bursektomi sayesinde;}

- Yırtık açığa çıkarılır.

- Bursa ve tendon ayrımı yapılır. Eğer retrakte bir yırtık varsa, gevşetme yapılması ve çevresinde ya da bursa ile arasında oluşan yapışıklıkların radyofrekans cihazıyla gevşetilerek tendon mobilizasyonun sağlanması çok önemlidir.

- Yırtık karakteri (şekli, boyutu) tanımlanır.

- Sütür yönetimi ve düğümleme kolaylaşır.

Bu aşamadan sonra tamire geçilebilir. Skop lateral portaldeyken Davidson ve Burkhart tarafından tanımlanan sınıflandırmaya göre yırtığın geometrisi, retraksiyon miktarı ve boyutu değerlendirilir. Tendonun mobilitesi ve redüksiyonu bir grasper ya da sütür taşıyıcı ile manipüle edilerek değerlendirilir (Şekil 3). Bunlar değerlendirildikten sonra, aşırı gerilim olmadan, anatomik bir tamir sağlanabilir. Tamir yöntemi lezyonun şekline göre belirlenir:

- Kresentik yırtıklar kolay mobilize edilebilir ve çok az gerginlikle direkt kemiğe sütür ankorlar ile tamir edilebilir. Eğer tendon uçlarında atrofik değişiklikler varsa shaver ya da punch yardımıyla uçlar debride edilip tazelendirilerek iyileşme potansiyeli artırılabilir.

- $\quad$ U, L ya da ters L şekilli yırtıklarda kanatların yeterli mobilizasyonu sağlanarak kenar konverjans tekniği uygulanarak gerilim azaltılarak, yırtık şekli kresentiğe çevrildikten sonra sütür ankorlar ile tamir sağlanabilir. Yan yana sütürler birkaç şekilde uygulanabilir; ayrı tek tek düğümlerle ya da devamlı (kontinu) sütürler şeklinde. Sütürlerin uygun yerleşimi için yırtığın apeksinin iyi belirlenmesi gereklidir; ilk (medial) sütür apeksten geçmelidir. U şekilli yırtıklarda ön ve arka kanatlar eşit olarak mobilize edilir, yani sütürler medialden laterale geçildikten sonra hangi portalden düğümün yerleştirildiği fark yaratmaz. Diğer taraftan L tipi yırtıklarda (ön kanat daha mobildir) sütürler medialden laterale ve anteriordan posteriora olacak şekilde geçilir ve posteriordan düğüm yerleştirilir. Tam tersi durum-

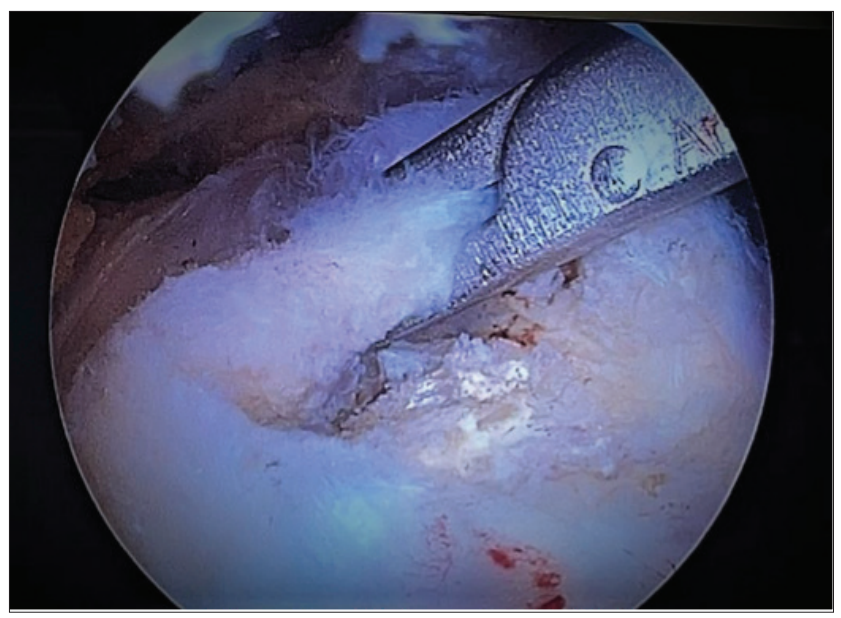

Şekil 3. Grasper ile tendon mobilizasyon kontrolü. 
da, ters L tipi yırtıklarda ise arka kanat daha mobil olduğu için sütür yine medialden laterale, ancak bu sefer posteriordan anteriora olacak şekilde geçilir ve düğüm anterior portalden yerleştirilir. Burada dikkat edilmesi gereken önemli bir nokta da arka taraftaki tendon kısmında delaminasyon olabileceği için sütürü geçerken tüm katmanları geçecek şekilde tendonun tüm kalınlığının sütüre dâhil edilmesidir. Bu da bağlama sırasında sıyrılmayı engelleyerek, tekrar yırtık gelişme ihtimalini en aza indirmeye katkı sağlayacaktır.

Yırtık paternini tanıyıp, tendonu mobilize ettikten ve gerilimi en aza indirdikten sonra birkaç farklı teknikle tendon tamiri yapılabilir: tek sıra, çift sıra (transosseöz eş değeri) ve artroskopik transosseöz tamir.

Ankorlar yerleştirilmeden önce footprint hazırlanmalıdır. Skop posterior portalden subakromial aralığa yerleştirilerek lateral portalden radyofrekans probu ile footprintteki yumuşak dokular temizlenerek shaver ile iyileşmeyi uyarmak için de kortikal abrazyon yapııı. Ön taraftaki yırtıklar için footprint hazırlığı için anterior-superior portal kullanılabilir.

Kortikal abrazyona alternatif olarak son dönemdeki çalışmalarda footprinte mikrokırık uygulamasının da tendon kemik iyileşmesinde etkili bir yöntem olduğu ortaya konmuştur. Mikrokırık yönteminin avantajı, özellikle osteoporotik olgularda kortikal kemiği zayıflatmayarak ankor pull-out riskini azalttığı yönündedir. Mikrokırık uygulamasının ankorlar yerleştirdikten sonra dügümleri bağlamadan önce, eklem sınırından tüberkülün lateral kenarına kadar tüm footprint boyunca uygulanması önerilmektedir.

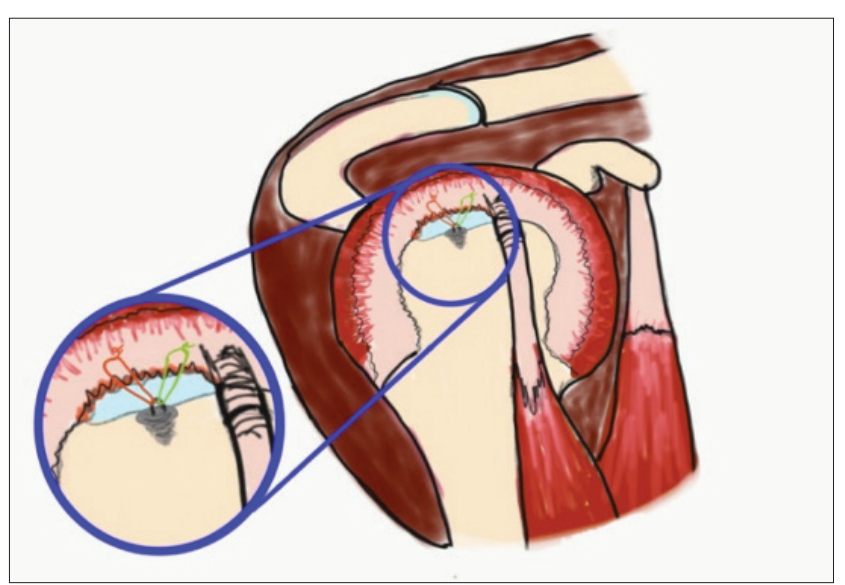

Şekil 4. Tek sıra tamir: Ankor yerleşimi ve sütürler yırtıktan geçirilip kayan kilitli düğüm yerleştirilerek tamirin tamamlanması.

\section{Tek Sıra Tamir Tekniği}

Medial ankorlar ile yırtık tek sıra şeklinde tamir edilerek yapılır. Boyutuna, fiksasyon türüne (düğümlü, düğümsüz), sütür sayısına ve materyaline göre farklı ankor çeşitleri mevcuttur. Son dönemde, ankorun yerleştirildiği delikten kemik iliği elemanlarının tamir sahasına akışına izin verebilecek tarzda ventilli ankorlar geliştirilmiştir. Tek sıra tamirde sıklıkla iki farklı renkte sütür yüklenmiş düğümlü metal ankorlar (Şekil 4) veya düğümsüz ankorlar (Şekil 5) tercih edilebilmektedir.

Kural olarak bir veya iki sütür ankor yırtık boyutuna göre yeterli olmaktadır. Geniş yırtıklarda nadiren üç ankor gerekmektedir.

Artroskop posterior portaldeyken, superior lateral portalden akromion lateral kenarından ankor yerleştirilir. $18 \mathrm{~g}$ iğne ile ankorun tam yerleşim noktası belirlenebilir.
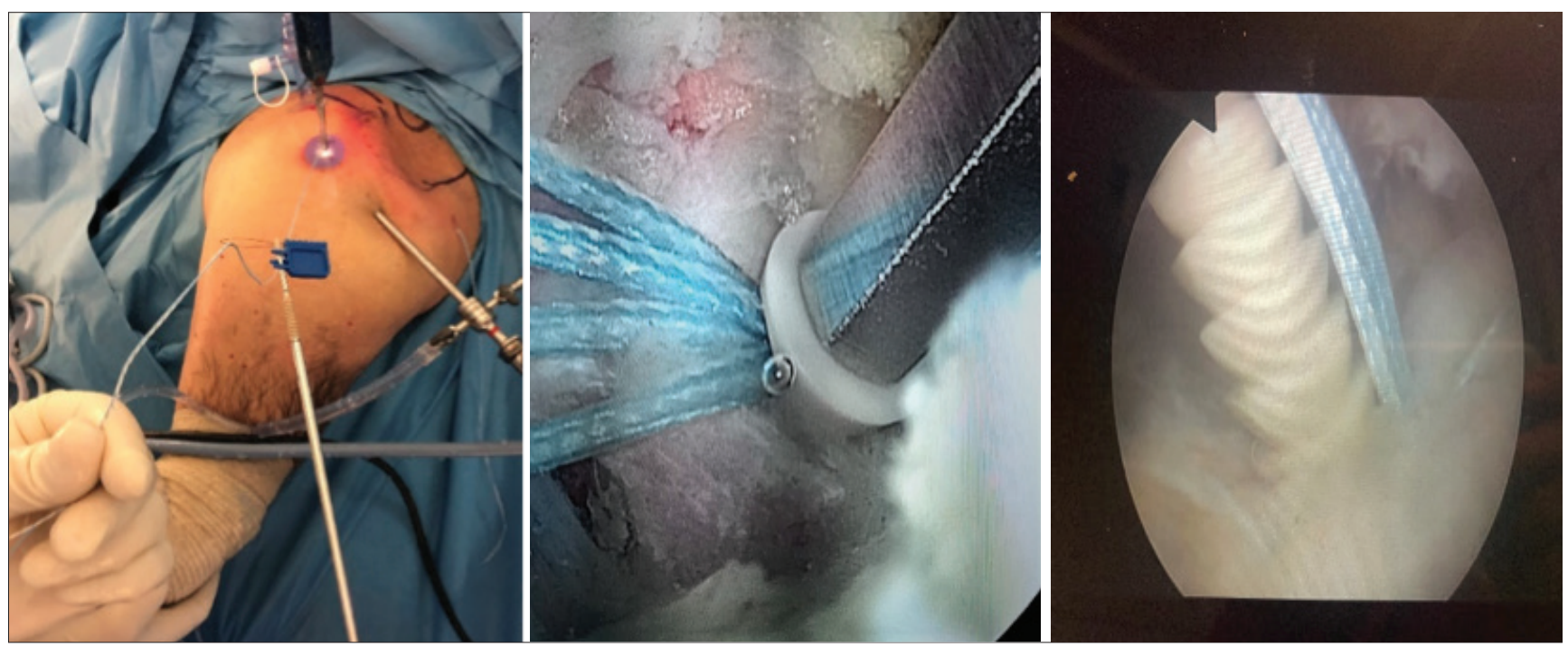

Şekil 5. Dügümsüz ankor ile tek sıra tamir. 
Çok önde yerleşimli yırtıklarda bazen anterior-superior portalden ankoru yerleştirmek gerekmektedir.

Portal oluşturduktan sonra metal ya da plastik kanül üzerinden ankor yerleştirilir. Ankoru daha güvenli yerleştirebilmek ve ankor tutucunun eğilmesini, kırılmasını engellemek için kanül ankorun yerleştirilmesi planlanan alan üzerine tamamen itilebilir.

Ankorlar, pull-out riskini en aza indirebilmek için tendona $45^{\circ}$ 'lik bir açıyla (Deadman'ın açı teorisine göre) humerus başı kıkırdak sınırında yırtığın tam ortasına ya da ön veya arka kenarına yakın olarak yerleştirilir. Birden fazla ankor kullanılacaksa önden arkaya doğru yerleştirilmelidir ve düğümleme sırası arkadan öne doğru kuvvet vektörleri yönünde olmalıdır. En uygun düğüm tipi tendon kalitesine ve gerilim olmadan tendon kenarlarından sütürun kaymasına izin verecek şekilde olmalıdır.

$L$ ya da ters $L$ yırtıklarda, matress sütür uygulayabilmek için bir ankor lezyonun tam köşesine yerleştirilmelidir. Böylelikle sütürün bir bacağı yırtığın ön kenarından, aynı sütürün diğer bacağı ise arka kenarından geçilerek yan yana tamir sağlanabilir.

\section{Çift Sıra Tamir Tekniği}

Medial ve lateral sıra olmak üzere iki sıra ankor ile uygulanır. Bu tekniğin amacı, tendonun kemik üzerindeki temas yüzeyini artırarak iyileşmeye katkı sağlamaktır. Bu teknik için birkaç uygulama yöntemi tarif edilmiştir; medial ve lateral sırada ayrı dügüumleme (Şekil 6 a-c), iki medial sütür ankor ve iki lateral düğümsüz ankor (SutureBridge) (Şekil 7 a-c, Şekil 8), iki medial sıra ankoru ve üç düğümsüz lateral ankor (elmas sırtı tamiri), medial ve lateral sırada düğümsüz ankor (SpeedBridge), medial sıra serbest sütür ve lateral sıraya düğümsüz ankor ile tamir. Bunlardan en sık tercih edilen suture bridge tekniğidir.

Footprint hazırlanıp, yırtık kenarları mobilize edildikten sonra medial ankorlar tarif edildiği şekilde yerleştirilir. Sütürlerin her biri matress sütür şeklinde dört yerden geçilir. Sütürler arkadan öne doğru dügümlenir. Arkadaki sütürün iki ucu ve ön taraftaki sütürün iki ucu farklı renklerde olacak şekilde kalır. Ön ve arkada sütürlerin en öndeki serbest uçları lateral portale taşınarak ön taraftaki medial ankorun lateralinde dügümsüz ankor ile tespit edilir. Diğer kalan iki sütür de aynı şekilde arka taraftaki

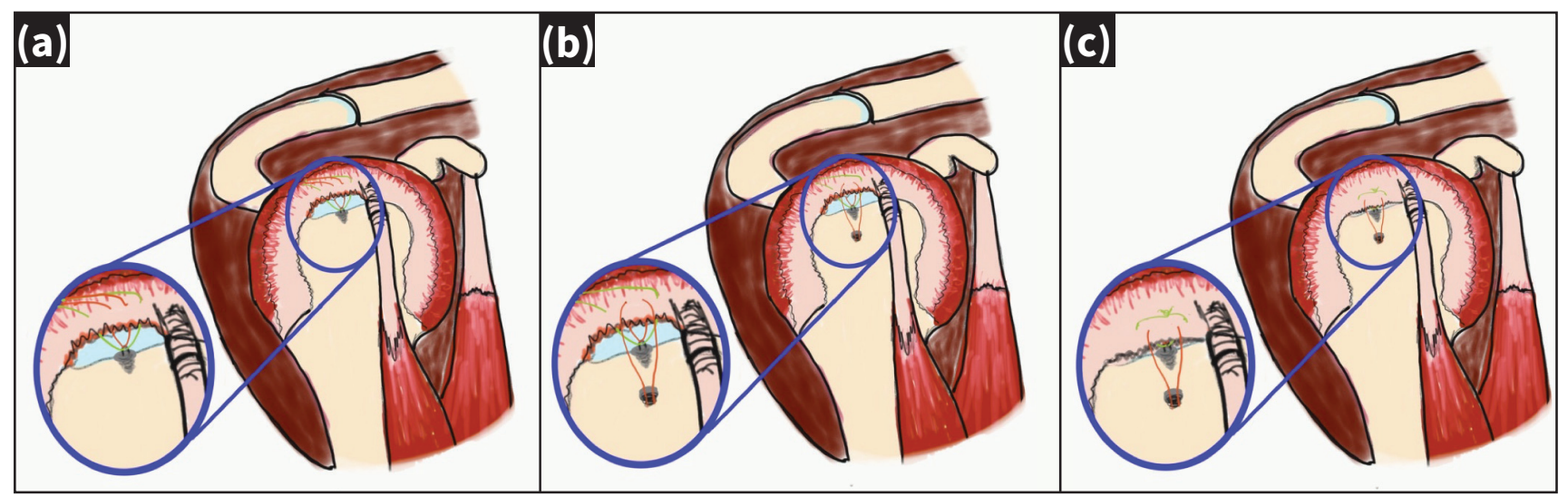

Şekil 6.a-c. Çift Sıra Tamir: Medial sıra ankorun yerleştirilmesi ve sütürlerin yırtık tendondan geçirilmesi (a). Düğümsüz ankor lateral sıraya yerleştirilerek yırtığın kapatılması (b). Medial ankora yüklü olan sütürün yüzey temasını sağlamak üzere düğümlenerek tamirin tamamlanması (c).
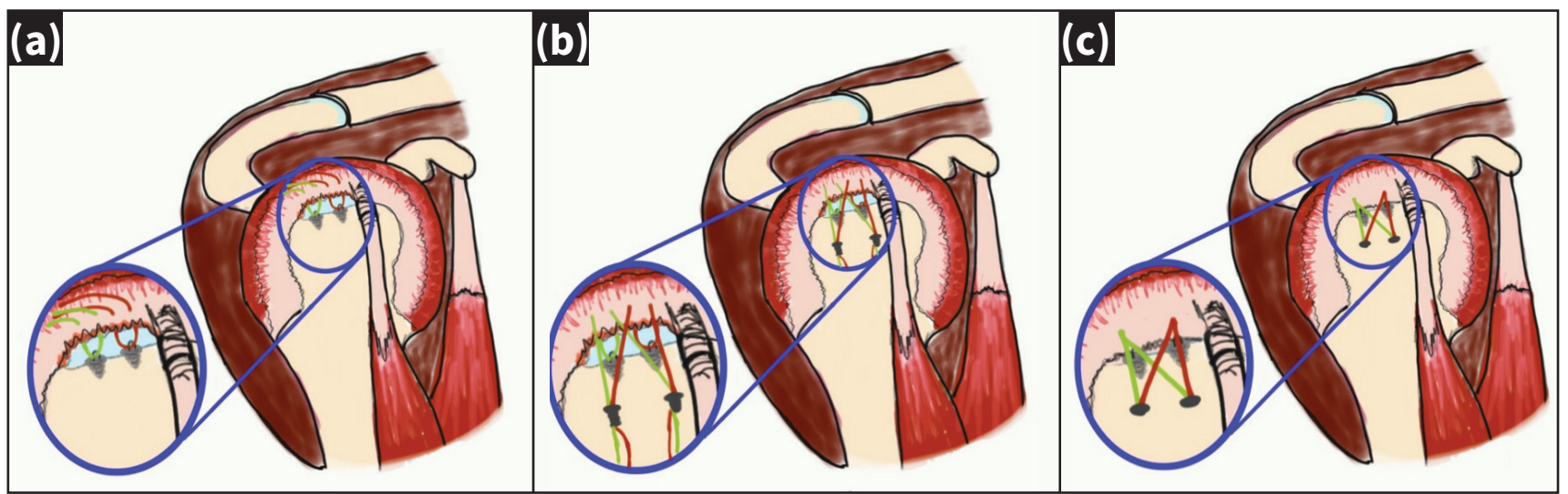

Şekil 7.a-c. Çift Sıra Tamir (SutureBridge ${ }^{\circledR}$ tekniğinin aşamaları): Medial ankorların yerleştirilmesi ve sütürlerin yırtık boyunda dört farklı bölgeden geçilmesi (a). Sütürlerin çaprazlayacak şekilde lateral sıra ankorlarına taşınması (b). Lateral düğümsüz ankorların tespitiyle tamirin tamamlanması (c). 

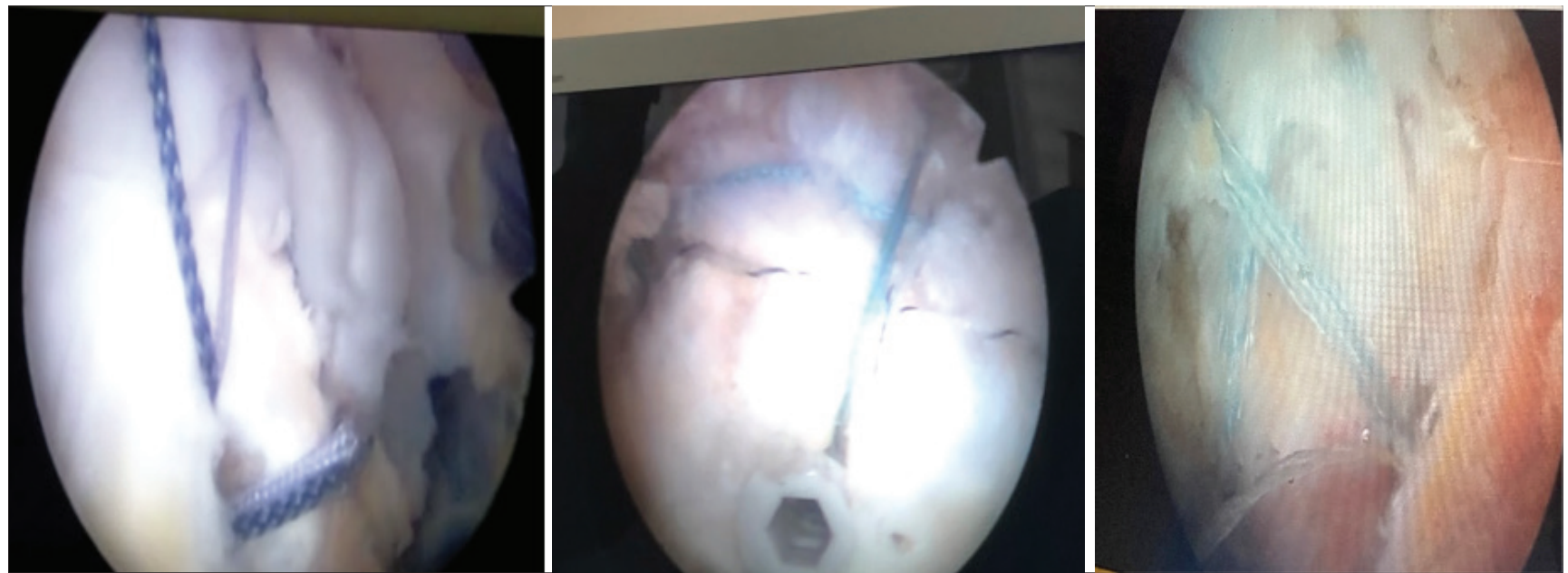

Şekil 8. SutureBridge tekniği ile çift sıra tamir ameliyat görüntüsü.

medial ankor lateralinde düğümsüz ankor ile tespit edilir. Böylelikle çaprazlayan bir sütür konfigürasyonu elde edilmiş olur. Lateral ankorun yerleşim açısının daha iyi biyomekanik stabilite sağladığı için vertikale yakın olması önerilmektedir. ${ }^{[25]}$ Sütür konfigürasyonundaki bu çapraz bağlantılar sayesinde yüzey temas alanı ve kemik tendon bileşkesindeki basınç artırılarak iyileşmenin desteklenmesi amaçlanır.

\section{Artroskopik Transosseöz Tamir}

Ankor kullanmadan artroskopik transosseöz tamir uygulanması için tek kullanımlık bir cihaz tasarlanmıştır (ArthroTunneler). Medialde normalde ankorun yerleştirildiği noktadan iki kemik tünel lateral kortekse ulaşacak şekilde açılır. Her bir tünelden üçer adet sütür geçirilebilerek farklı konfigürasyonlarda tamir konfigürasyonları oluşturulabilir. Günümüzde bu uygulamanın etkinliğini değerlendiren klinik bir çalışma yoktur ancak ankor kullanılmasına bağlı oluşabilecek pull-out gibi riskler azaltılması ve ekonomik açıdan da fayda sağlaması söz konusudur. Yakın dönemde çift sıra teknik ile karşılaştırması yapılan biyomekanik çalışmada daha iyi biyomekanik stabilite bildirilmiştir. ${ }^{[26]}$

\section{AMELIYAT SONRASI BAKIM}

Tamir türünden bağımsız olarak, tamir uygulanan tüm hastalar dört hafta boyunca nötral rotasyonda ve $20^{\circ}$ abduksiyonda immobilize edilmektedir. Bandaj sonlandırıldıktan sonra aşağıdaki gibi rehabilitasyon protokolü takip edilmektedir. ${ }^{[13]}$

- Evre 1 (Ameliyat sonrası 4-8. hafta): Skar formasyonuna bağlı oluşan yapışıklıkların açılması, eklem hareket açıklığının sağlanmasına yönelik pasif mobilizasyon.
- $\quad$ Evre 2 (Ameliyat sonrası 9-12. hafta): Kapalı kinetik zincir egzersizleri ile rotator manşet, subskapularis, biseps, deltoid, pektoralis majör ve skapular stabilizatörlerin güçlendirilmesi.

- Evre 3 (Ameliyat sonrası 13-16. hafta): Açık kinetik zincir egzersizleri, proprioseptif ve pliometrik egzersizler ile postural rehabilitasyona başlanır.

Ağır işlere ve rekabetçi sportif faaliyetlere ameliyat sonrası altıncı aydan sonra izin verilir.

Rotator manşet tamirleri açık, mini-açık veya artroskopik yöntemlerle benzer klinik sonuçlarla tamir edilebilmektedir. ${ }^{[27]}$ Artroskopik teknikler, cerrahi alanda daha az morbidite, kısa ameliyat süresi ve cerrahi sonrasında erken iyileşme gibi küçümsenmeyecek ölçüde avantajlar sunmaktadır. Artroskopik tamir sonrası iyi klinik sonuçlara rağmen özellikle geniş masif yırtıklarda tekrar yırtık oranı yüksektir. ${ }^{[28]}$ Tamir bütünlügünü değerlendirmek için farklı görüntüleme yöntemleri (ultrasonografi, BT, MR, MR artrografi) ile birtakım sınıflamalar tanımlanmıştır. Ancak tamir bütünlüğü ile klinik sonuçlar arasındaki ilişki hâlen tartışmalı bir konudur. Bazı çalışmalarda komplet ya da kısmi tekrar yırtık ile iyileşmiş rotator manşeti olan hastalar arasında anlamlı klinik farklılık olmadığı gösterilmiş; tam tersi bazı çalışmalarda ise, tendon bütünlüğü sağlanan hastalarda anlamlı derecede daha iyi klinik sonuçlar olduğu bildirilmektedir. ${ }^{[29]}$ Artroskopik tamir sonrası humerus başının proksimale migrasyonunun değerlendirildiği çalışmalarda çift sıra tamir uygulanan hastalarda akromiohumeral mesafenin daha çok korunduğu gösterilmiştir. ${ }^{[30,31]}$ Bu durumun çift sıra tamirlerde, hastalığın yırtık artropatisine ilerleme riskini azaltabilecek bir unsur olabileceği dikkat çekmektedir.

Tekrar yırtık oranlarını azaltabilmek adına, gerilim oluşturmadan anatomik tamir yapabilmek ve kemik ten- 
don bileşkesinde yeterli teması sağlayabilmek için farklı artroskopik teknikler geliştirilmiştir. Birçok çalışma çift sıra tekniğin daha iyi biyomekanik özellikler sağladığını gösterse de ${ }^{[32]}$, güncel derleme çalışmalarında çift sıra tamirin, tek sıra tamire ne klinik açıdan ne de yapısal (tamir bütünlügü) açıdan bir üstünlügü olmadığı gösterilmiştir. ${ }^{[33]}$ Dahası, çift sıra tamir sonrası tekrar yırtıkların değerlendirildiği klinik çalışmalarda, yeniden yırtığın medial ankor seviyesinde olduğu izlenmiştir. Çift sıra tamir kemik tendon bileşkesinin yüzey alanını artırmakta ancak aynı zamanda medial sıradaki gerginliğin de artmasına neden olmaktadır. ${ }^{[32]}$

Teknik gelişmelere rağmen, tamir sonrası tendon bütünlügü birtakım biyolojik faktörlerden negatif olarak etkilenmektedir. Bunlar, kadın cinsiyet, semptom süresi, yırtık genişliği, Goutallier Evre 2 ve üzeri yağlı dejenerasyon, kas atrofisi, kemik mineral dansitesi, diyabet ve sigara kullanımıdır. ${ }^{[34]}$ içilen sigara sayısı ile yırtık boyutu arasında doğru orantı vardır.

Yaş, çelişkili bir faktördür. Bazı çalışmalar yapısal sonuçlarla ileri yaş arasında ters korelasyon olduğunu göstermekteyken ${ }^{[35]}$ bazı çalışmalar ise yaşlı hastalarda daha iyi sonuçlar bildirmektedir. ${ }^{[36]}$ Yağlı dejenerasyonun kötü cerrahi sonuçlarla ilişkisi hem klinik açıdan hem de yapısal açıdan net olarak ortaya konmuştur. ${ }^{[37]}$ Yağlı dejenerasyonun tamir sonrası ilerlemesinin durdurulabildiği gösterilse de gitgide ve geri dönüşümsüz olarak ilerlemektedir. ${ }^{[38]}$

Son olarak, yeni bir çalışma tekrar yırtıkların cerrahi sonrası ilk üç ayda olduğuna dikkat çekmektedir. Tamir bölgesinin vaskülarizasyonu ameliyat sonrası birinci ve ikinci aylarda artarak sonrasında zamanla azaldığı için, bu durumu vaskülarizasyonla ilişkilendirmek uygun olabilir.

Rotator manşet yırtıkları dejeneratif ya da travmatik nedenlerden olmaktadır. Dejeneratif yırtıklar omuzda en sık görülen patolojidir. Klinik değerlendirme ve MR bulguları tanıda önemli yer teşkil eder. Yaşlı hastalarda, ağrının başlaması ve güç kaybı daha önceden var olan bir yırtığın genişlemesine işaret eder. Küçük yırtıklar için ilk olarak konservatif yöntemler uygulanır. Konservatif yöntemlerden fayda görmeyen küçük yırtıklar, orta ve geniş yırtıklarda mutlaka cerrahi tedavi uygulanmalıdır. Farklı artroskopik tekniklerin birbirine üstünlüğü net olarak ortaya konmuş olmasa da başarılı artroskopik rotator manşet tamiri için yırtık paterninin iyi anlaşılması gerekmektedir.

Sonuç olarak, rotator manşet yırtıkları, ileri yaş aktiviteleri arttıkça ve insan ömrü uzadıkça ortopedi ve travmatoloji uzmanlarının karşısına daha sıklıkla çıkmaktadır. Gerçek patolojiyi ortaya koyup, uygun tedaviyi gerek cerrahi gerekse konservatif olarak planlayarak yapmak ve ardından uygun rehabilitasyon protokollerini vermek tedavinin ana hatlarıdır. İyi tedavi edilmiş bir manşet yırtığının klinik sonuçları oldukça yüz güldürücü olacaktır. Farklı artroskopik tekniklerin birbirine üstünlüğü net olarak ortaya konmuş olmasa da başarılı artroskopik rotator manşet tamiri için yırtık paterninin iyi anlaşııması gerekmektedir.

\section{KAYNAKLAR}

1. Yamamoto A, Takagishi K, Osawa T, Yanagawa T, Nakajima D, Shitara $\mathrm{H}$. Prevalence and risk factors of a rotator cuff tear in the general population. J Shoulder Elb Surg 2010;19:116-20. Crossref

2. Lawrence RL, Moutzouros V, Bey MJ. Asymptomatic rotator cuff tears. JBJS Rev 2019;7(6):1-9. Crossref

3. Itoi E. Rotator cuff tear: physical examination and conservative treatment. J Orthop Sci 2013;18:197-204. Crossref

4. Yamaguchi K, Ditsios K, Middleton WD, Hildebolt CF, Galatz LM, Teefey SA. The demographic and morphological features of rotator cuff disease: a comparison of asymptomatic and symptomatic shoulders. J Bone Jt Surg 2006;88A:1699-704. Crossref

5. Mall NA, Kim HM, Keener JD, Steger May K, Teefey SA, Middleton WD. Symptomatic progression of asymptomatic rotator cuff tears: a prospective study of clinical and sonographic variables. J Bone Jt Surg 2010;92A:2623-33. Crossref

6. Harris JD, Pedroza A, Jones GL. MOON (Multicenter Orthopedic Outcomes Network) Shoulder Group. Predictors of pain and function in patients with symptomatic, atraumatic full-thickness rotator cuff tears: a time-zero analysis of a prospective patient cohort enrolled in a structured physical therapy program. Am J Sports Med 2012;40:359-66. Crossref

7. Yamaguchi K, Tetro AM, Blam O, Evanoff BA, Teefey SA, Middleton WD. Natural history of asymptomatic rotator cuff tears: a longitudinal analysis of asymptomatic tears detected sonographically. J Shoulder Elb Surg 2001;10:199-203. Crossref

8. Matsen FA, Cordasco FA, Sperling JW, Lippitt SB, Rockwood CA. Rotator cuff. In: Rockwood and Matsen's The Shoulder. Elsevier: Washington, 2021.

9. Shimizu T, Itoi E, Minagawa H, Pradhan RL, Wakabayashi I, Sato K. Atrophy of the rotator cuff muscles and site of cuff tears. Acta Orthop Scand 2002;73:40-3. Crossref

10. Kim HM, Dahiya N, Teefey SA, Middleton WD, Stobbs G, Steger May K. Location and initiation of degenerative rotator cuff tears: an analysis of three hundred and sixty shoulders. J Bone Jt Surg 2010;92A:1088-96. Crossref

11. Burkhart SS, Esch JC, Jolson RS. The rotator crescent and rotator cable: an anatomic description of the shoulder's "suspension bridge". Arthroscopy 1993;9:611-6. Crossref

12. Mall NA, Lee AS, Chahal J, Sherman SL, Romeo AA, Verma NN. An evidenced-based examination of the epidemiology and outcomes of traumatic rotator cuff tears. Arthroscopy 2013;29:366-76. Crossref 
13. Burkhart SS, Lo IK. Arthroscopic rotator cuff repair. J Am Acad Orthop Surg 2006;14:333-46. Crossref

14. Snyder SJ. Evaluation and treatment of the rotator cuff. Orthop Clin North Am 1993;24:173-92. Crossref

15. Davidson J, Burkhart SS. The geometric classification of rotator cuff tears: a system linking tear pattern to treatment and prognosis. Arthroscopy 2010;26:417-24. Crossref

16. Ok JH, Kim YS, Kim JM, Yoo TW. Learning curve of office-based ultrasonography for rotator cuff tendons tears. Knee Surg Sports Traumatol Arthrosc 2013;21:1593-7. Crossref

17. Wall LB, Teefey SA, Middleton WD, Dahiya N, Steger May K, Kim HM. Diagnostic performance and reliability of ultrasonography for fatty degeneration of the rotator cuff muscles. J Bone Jt Surg 2012;94A:e83. Crossref

18. Patte D. Classification of rotator cuff lesions. Clin Orthop Relat Res 1990;254:81-6. Crossref

19. Goutallier D, Postel JM, Bernageau J, Lavau L, Voisin MC. Fatty muscle degeneration in cuff ruptures: pre- and postoperative evaluation by CT scan. Clin Orthop Relat Res 1994;304:78-83. crossref

20. Fuchs B, Weishaupt D, Zanetti M, Hodler J, Gerber C. Fatty degeneration of the muscles of the rotator cuff: assessment by computed tomography versus magnetic resonance imaging. J Shoulder Elb Surg 1999;8:599-605. Crossref

21. Slabaugh MA, Friel NA, Karas V, Romeo AA, Verma NN, Cole BJ. Interobserver and intraobserver reliability of the Goutallier classification using magnetic resonance imaging: proposal of a simplified classification system to increase reliability. Am J Sports Med 2012;40:1728-34. Crossref

22. González RR. Direct magnetic resonance arthrography, indirect magnetic resonance arthrography, and computed tomography arthrography for rotator cuff lesions and superior labral anterior and posterior tears: state of the art. Radiol Engl Ed 2013;55(4):283-93. Crossref

23. Tudisco C, Bisicchia S, Savarese E, Fiori R, Bartolucci DA, Masala S. Single-row vs. double-row arthroscopic rotator cuff repair: clinical and 3 Tesla MR arthrography results. BMC Musculoskelet Dis 2013;14(43). Crossref

24. Pedowitz RA, Yamaguchi K, Ahmad CS, Burks RT, Flatow EL, Green A. Optimizing the management of rotator cuff problems. J Am Acad Orthop Surg 2011;19:368-79. Crossref

25. Acan AE, Hapa O, Horoz L, Kara A, Havitçıŏlu H. Effects of a lateral row anchor position on the suture holding strength of a double-row knotless fixation in rotator cuff repair. Jt Dis Relat Surg 2018;29(1):46-51. Crossref

26. Salata MJ, Sherman SL, Lin EC, Sershon RA, Gupta A, Shewman E. Biomechanical evaluation of transosseous rotator cuff repair: do anchors really matter? Am J Sports Med 2013;41:283-90. Crossref

27. van der Zwaal P, Thomassen BJ, Nieuwenhuijse MJ, Lindenburg $\mathrm{R}$, Swen JW, van Arkel ER. Clinical outcome in all-arthroscopic versus mini-open rotator cuff repair in small to medium-sized tears: a randomized controlled trial in 100 patients with 1-year follow-up. Arthroscopy 2013;29(2):266-73. Crossref
28. Charousset C, Grimberg J, Duranthon LD, Bellaiche L, Petrover D. Can a double-row anchorage technique improve tendon healing in arthroscopic rotator cuff repair?: a prospective, nonrandomized, comparative study of double-row and single-row anchorage tech-niques with computed tomographic arthrography tendon healing assessment. Am J Sports Med 2007;35:1247-53. Crossref

29. Miller BS, Downie BK, Kohen RB, Kijek T, Jacobson JA, Hughes RE. When do rotator cuff repairs fail? Serial ultrasound examination after arthroscopic repair of large and massive rotator cuff tears. Am J Sports Med 2011;39:2064-70. Crossref

30. Turan K, Çabuk H, Köroğlu C, Öztürk Ç. Increased acromiohumeral distance in a double-row arthroscopic rotator cuff surgery compared to a single-row surgery after 12 months. J Orthop Surg 2021;16(1):1-7. Crossref

31. Kholinne E, Kwak JM, Sun Y, Kim H, Park D, Koh KH, et al. The relationship between rotator cuff integrity and acromiohumeral distance following open and arthroscopic rotator cuff repair. SICOT-J 2021;7:23. Crossref

32. Baums MH, Spahn G, Buchhorn GH, Schultz W, Hofmann L, Klinger HM. Biomechanical and magnetic resonance imaging evaluation of a single- and double-row rotator cuff repair in an in vivo sheep model. Arthroscopy 2012;28:769-77. Crossref

33. Gürpınar T, Polat B, Tekin SB, Polat AE, Çarkçı E, Öztürkmen $Y$. Comparison of early clinical results and re-tear rates of transosseous-equivalent rotator cuff repairs with or without medial knots. Jt Dis Relat Surg 2019;30(3):193-200. Crossref

34. Carbone S, Gumina S, Arceri V, Campagna V, Fagnani C, Postacchini F. The impact of preoperative smoking habit on rotator cuff tear: cigarette smoking influences rotator cuff tear sizes. J Shoulder Elb Surg 2012;21:56-60. Crossref

35. Robinson PM, Wilson J, Dalal S, Parker RA, Norburn P, Roy BR. Rotator cuff repair in patients over 70 years of age: early outcomes and risk factors associated with re-tear. Bone Jt J 2013;95B:199-205. Crossref

36. Rebuzzi E, Coletti N, Schiavetti S, Giusto F. Arthroscopic rotator cuff repair in patients older than 60 years. Arthroscopy 2005;21:48-54. Crossref

37. Oh JH, Kim SH, Ji HM, Jo KH, Bin SW, Gong HS, et al. Prognostic factors affecting anatomic outcome of rotator cuff repair and correlation with functional outcome. Arthroscopy 2009;25:309. Crossref

38. Yamaguchi H, Suenaga N, Oizumi N, Hosokawa Y, Kanaya F. Will preoperative atrophy and fatty degeneration of the shoulder muscles improve after rotator cuff repair in patients with massive rotator cuff tears? Adv Orthop 2012;2012(195876). Crossref 